\title{
INCLUSÃO E CEGUEIRA: Encontros na escola regular
}

\author{
Inclusion and blindness: Meetings at a regular school
}

\author{
Luara Fernandes França Lima ${ }^{[a]}$, Marcia Moraes ${ }^{[b]}$ \\ [a] Psicóloga pela Universidade Federal Fluminense (UFF), Niterói, RJ - Brasil, email: luafflima@gmail.com \\ [b] Professora associada do Departamento de Psicologia da Universidade Federal Fluminense (UFF), vinculada ao programa de \\ Pós-Graduação em Psicologia da Universidade Federal Fluminense, Niterói, RJ - Brasil, e-mail: mmoraes@vm.uff.br
}

\begin{abstract}
Resumo
Este trabalho tem como objetivo pensar as práticas de inclusão de jovens com deficiência visual na escola regular. A partir da contribuição teórica de Michel Foucault, compreende-se a anormalidade e a deficiência como conceitos engendrados numa construção histórica por meio de práticas e discursos que produzem sujeitos. Refere-se à corrente de pensamento inaugurada por Félix Guattari para entender a concepção de produção de subjetividade como forças em jogo. A pesquisa foi desenvolvida numa escola regular inclusiva, situada no Rio de Janeiro. Com entrevistas e grupos de discussão com alunos, professores e funcionários, foi possível fazer o desenho de algumas forças que ali se conectam na perspectiva de construção da inclusão. A política de inclusão implementada no Brasil em 2001 através do Plano Nacional de Educação do Governo Federal faz daquele espaço palco de "encontros mistos" entre cegos e videntes, colocando em cena diversas concepções acerca da cegueira. A partir disso procura-se pensar as relações que surgem neste contexto e de que modo o manejo desses encontros pode se constituir como a produção de um coletivo potente e inclusivo.
\end{abstract}

Palavras-chave: Inclusão. Deficiência. Subjetividade.

\section{Abstract}

This paper investigates school inclusive practices with youths with visual disabilities. Based on Michel Foucault's theory, we understand abnormality and disability as concepts historically produced through practices and discourses that bring into being the subjects. We are also based on Felix Guattari's conception of subjectivity production as forces. The research was developed in an inclusive regular school, in Rio de Janeiro. Through interviews and discussion groups with that school students, teachers and employees, it was possible to map some forces 
that was at stake on that place and which was functioning in order to produce the inclusion. The inclusion policy implemented in Brazil in 2001, trough an Educational National Plan, offers the opportunity that the school becomes a stage where takes place "hybrid meetings" amongst people with visual disabilities and people without these disabilities. By these means, different conceptions of blindness are performed. Finally, we ask the ways in which these "hybrid meetings" are handled to produce an inclusive group.

Keywords: Inclusion. Disability. Subjectivity.

\section{INTRODUÇÃO}

Neste trabalho será apresentado o relato de experiência desenvolvido no campo da deficiência visual. O foco de investigação foi acompanhar o modo como ocorria a inclusão de alunos com deficiência visual, egressos de uma instituição de ensino especial (IE), em uma escola pública regular inclusiva (ERI), ambas as instituições localizadas no Rio de Janeiro. ${ }^{1}$

A escola se configura como importante dispositivo produtor de subjetividade e adquire um papel fundamental na política de inclusão. Nossa interrogação aponta para o conhecimento de como isso é engendrado no cotidiano das organizações e das vivências subjetivas, sendo importante identificar que forças se conectam no contexto escolar da ERI.

Acompanhando as relações que ali se constituem, entre alunos que enxergam e aqueles com deficiência visual, entre professores e alunos, entre a escola e os alunos da Educação Especial, entre as concepções hegemônicas de cegueira e a experiência de quem não enxerga, foi emergindo os sentidos que a inclusão adquire no encontro com a cegueira e a forma como são manejados os "encontros mistos" (Martins, 2006) ${ }^{2}$ possibilitados pela política pública.

A metodologia utilizada na realização deste trabalho o inclui na esteira das pesquisas participativas. O que interessa não é somente observar como se dá a inclusão, mas incluir a todos nesta discussão. Por meio de entrevistas e rodas de conversa, fomos fomentando o debate de questões acerca da inclusão, buscando refletir sobre os vetores que se cruzam nesta prática.

\section{Cegueira e história: a hegemonia da normalidade}

Nos últimos vinte anos, acompanhando a tendência mundial, o governo brasileiro tem apostado na reformulação das políticas para a Educação Especial do país. A direção dessas políticas aponta para a necessidade de construção de uma sociedade mais justa e mais igualitária, caminhando no sentido de uma sociedade inclusiva. Porém, este movimento para a inclusão esbarra numa concepção de cegueira, construída historicamente, que a associa à incapacidade, à desgraça, e que tem muita força, erigindo inúmeras barreiras às pessoas com deficiência visual.

Martins (2006), apostando numa abordagem construtivista, ${ }^{3}$ considera que a concepção hegemônica da cegueira na cultura ocidental, como tragédia ou infortúnio, não é natural, e sim fruto de uma construção histórica que engendra diversos fatores e varia de acordo com o contexto histórico-cultural. O autor aponta que é a partir da conjunção entre a cegueira e a cultura, que surge determinada concepção acerca da ausência de uma função sensorial, a visão.

\footnotetext{
1 Este trabalho foi realizado segundo a ética de pesquisa com seres humanos. Neste sentido, omitimos os nomes das Instituições nas quais a pesquisa foi realizada. Uma delas é uma instituição pública especial, voltada para o ensino e a educação da pessoa com deficiência visual. Já outra é uma escola pública regular de ensino que recebe os alunos egressos do $9^{\circ}$ ano do ensino fundamental daquela instituição especial. Neste texto, chamaremos de IE a instituição especial e de ERI a escolar regular inclusiva.

2 O conceito de "encontros mistos" elaborado por Bruno Sena Martins (2006) será melhor discutido mais adiante.

3 Que se difere do construtivismo de Piaget que define a priori etapas do desenvolvimento cognitivo pelas quais toda criança passaria ao longo de sua vida. A abordagem construtivista de Martins (2006) se refere a uma construção das práticas sociais na história.
} 
A partir do século XVII, com o advento da modernidade, movimento de transformação do paradigma do conhecimento, com a ascensão do racionalismo e do conhecimento científico, tem início a "emergência de conhecimentos e vontades de saber que adquiriram o prestígio canônico de ciência, o surgimento de inovações tecnológicas capazes de confrontar a precariedade humana na relação com a natureza" (Martins, 2006, p. 59). As interpretações do mundo baseadas em fenômenos místicos são deslocadas para dar lugarà racionalidade moderna, que certamente incidia também sobre as questões acerca da cegueira.

Com a valorização do conhecimento científico, articulada à prática de internação asilar dos indivíduos improdutivos, incluindo-se aí os cegos, a cegueira é apropriada pela medicina como um objeto de interesse para este campo de saber e, em oposição à forma de compreendê-la até então, passa a ser concebida pelo paradigma biomédico do corpo, que a considera do ponto de vista funcional. Foucault (2007) identifica neste período histórico uma crescente objetificação do corpo, e a partir deste olhar, a definição de uma norma, de um tipo de corpo normal, que se opõe a qualquer corpo que possua alguma diferença. A cegueira é entendida agora como ausência do sentido da visão, que representa uma disfunção do corpo, um desvio em relação à norma, um déficit, uma deficiência. Essa mudança de paradigma provoca transformações na maneira de lidar com a deficiência e a emergência de inúmeras barreiras físicas, sociais e morais àqueles considerados deficientes.

Foucault (1996), numa genealogia das formas de saber e poder engendradas ao longo da história, faz uma comparação entre as instituições disciplinares dos séculos XVII e XVIII e aquelas que começam a surgir a partir do século XIX pela transformação dos procedimentos de internamento e controle de um período para o outro. Em relação às práticas de internamento, o que se fazia nos séculos XVII e XVIII, e que era muito comum principalmente na França, era internar um indivíduo pela sua vida desviante e desordenada, por sua marginalização em relação à sua família ou ao seu grupo social. Aplicava-se uma "reclusão de exclusão" (Foucault, 1996, p. 114). O indivíduo era excluído do contato com a sociedade, sem nenhum outro objetivo que não o seu isolamento.

No século XIX a prática do internamento nas fábricas-prisões, nas escolas ou no hospital psiquiátrico, por exemplo, tinha como finalidade a produção de um produto para o consumo, para a formação ou correção. $O$ objetivo não era excluir, mas fixar os indivíduos a determinados "aparelhos de normalização" (Foucault, 1996, p. 114). Nas palavras do autor:

pode-se, portanto, opor a reclusão do século XVIII, que exclui os indivíduos do círculo social, à reclusão que aparece no século XIX, que tem por função ligar os indivíduos aos aparelhos de produção, formação, reformação ou correção de produtores. Trata-se, portanto, de uma inclusão por exclusão (Foucault, 1996, p. 114).

Nos séculos XVIII e XIX, o corpo é o lócus privilegiado para as práticas de controle dos indivíduos. Primeiramente como o corpo que é supliciado, castigado fisicamente, mas depois "deve ser formado, reformado, corrigido, [...] deve adquirir aptidões, receber um certo número de qualidades, qualificar-se como um corpo capaz de trabalhar" (Foucault, 1996, p. 119). Por meio das grandes instituições disciplinares - escolas, hospitais, prisões, fábricas - que surgiram nesta época, estava estruturado um aparato que tinha não somente a função de apropriar-se e extrair a máxima quantidade de tempo dos indivíduos, mas também de controlar, formar seus corpos, valorizá-los, segundo determinado sistema.

Nesta lógica enquadram-se as escolas especiais para pessoas cegas que começam a surgir com o propósito de promover a adaptação destes sujeitos pela educação. As pessoas com alguma deficiência eram assim classificadas pelo saber médico como tendo um desvio e enviadas para as instituições as quais caberiam reformar aquele corpo, normalizá-lo. Esta pessoa estaria incluída numa instituição de ensino, porém excluída do convívio em sociedade, operando-se, assim, uma “inclusão por exclusão" (Foucault, 1996, p. 114). A segregação enquanto produção da modernidade se institucionaliza através de diversas práticas, reafirmando-se no contexto inclusivo atual.

As técnicas de disciplinarização (Foucault, 2001) visavam à correção dos indivíduos desviantes. Porém, deparavam-se frequentemente com situações em que se colocava a impossibilidade deste objetivo, fazendo surgir a categoria que Foucault vai nomear de "incorrigível", na qual se enquadrava a cegueira. Nos séculos XVII e XVIII ocorre o "nascimento técnico-institucional da 
cegueira" (Foucault, 2001, p. 416). A cegueira se institucionaliza como um desvio, frequentemente incurável, através de todo um aparato científico e social que lhe dá suporte.

Nessa mesma época, porém, o "conhecer" se revela como aspecto central do ideário iluminista, fazendo surgir num outro movimento, possibilidades para o cego de ter acesso ao conhecimento, importante fator de valorização social. Denis Diderot, Louis Braille e Valentin Haüy ${ }^{4}$ foram figuras fundamentais na afirmação de outro modo de pensar a cegueira.

Essas iniciativas foram extremamente importantes, pois valorizando as formas de conhecer e de estar no mundo próprias daqueles que não possuíam o sentido da visão e dando importância à educação das crianças cegas, abriase para estas pessoas outras possibilidades de existência. A partir da difusão do sistema Braille, acreditou-se que a limitação sensorial não representaria o impedimento de suas atividades e da realização de suas expectativas. No entanto, mesmo que a modernidade tenha consagrado o Braille como uma forma de aquisição de conhecimento, isto se associou a um processo de institucionalização e objetificação da cegueira (Martins, 2006). Assim como a medicina começa a atuar nos hospitais, o ensino dos cegos vai se realizar nos internatos, perpetuando-se a lógica da exclusão. Os colégios internos, como o Instituto Real dos Jovens Cegos, em Paris, reconhecido como pioneiro, e os asilos, eram alguns dos instrumentos que contribuíam para a institucionalização da cegueira e para a perpetuação desta lógica, tendo permanecido até o século XX.

Ao longo da história de constituição da noção de cegueira como déficit ou como desvio ante a normalidade visuocêntrica, construiu-se também uma série de práticas em prol da integração dessas pessoas no contexto social. O tema da exclusão social é recorrente no século XX.

O movimento de questionamento da institucionalização manicomial e a chegada, nos Estados Unidos, de militares deficientes, retornando das guerras empreendidas pelos norte-americanos, dispararam discussões a respeito das políticas voltadas para as pessoas com deficiências em todo mundo. A partir da década de 1960 começa-se a debater a integração das pessoas com deficiência e cresce o número de instituições voltadas à reabilitação, tratamento e educação especializados (Sassaki, 2003).

Até a década de 1990 praticava-se a integração das pessoas com deficiência, articulada a práticas assistencialistas de cuidado, visando sua adaptação à sociedade, no sentido de prepará-las para conviver com os "normais" em nível de igualdade. No entanto, esse tipo de prática se deparava com a impossibilidade da realização deste ideal, passando a ser alvo de questionamentos. A lógica da integração experimenta seu limite e com a valorização da diferença contida na deficiência inaugura-se o princípio da inclusão (Sassaki, 2003).

\section{A inclusão ante um contexto de normalização social}

Segundo Martins (2005), as políticas públicas serão realmente efetivas se puderem produzir questionamento a respeito das concepções hegemônicas sobre a deficiência, como déficit ou infortúnio. No entanto, o autor constata que no cenário político em Portugal, o investimento do Estado tem sido na construção de uma rede de segurança social incapaz, por si só, de transformar de modo efetivo esta concepção de deficiência. ${ }^{5}$

Pesquisando a legislação educacional vigente, aparece como um marco muito importante na direção das políticas para a Educação Especial, a Declaração de Salamanca, elaborada na Conferência Mundial de Educação Especial em 1994, na Espanha. Este documento afirma a necessidade de construirmos uma sociedade que garanta às pessoas com deficiência o acesso à educação, reafirmando o compromisso com a Educação para Todos ${ }^{6}$. Considera-se que a escola deve considerar as características singulares e as necessidades especiais de todas as crianças e não apenas voltar-se para aquelas com alguma deficiência física ou mental. O texto do referido documento

\footnotetext{
${ }^{4}$ Conferir a este respeito, Lima, 2008.

5 Para o aprofundamento das discussões acerca de como essa discussão se fez presente no Brasil, conferir Lima (2008).

6 O compromisso com a Educação para Todos foi firmado na Conferência Mundial em Educação para Todos, realizada em 1990, em Jomtien, na Tailândia. Este encontro procurou definir objetivos e estratégias para que cada criança no mundo tivesse o direito à educação garantido.
} 
afirma que "escolas regulares que possuam tal orientação inclusiva constituem os meios mais eficazes de combater atitudes discriminatórias criando-se comunidades acolhedoras, construindo uma sociedade inclusiva e alcançando educação para todos" (Declaração de Salamanca, 1994, p. 1).

No entanto, para que este processo se concretize, indica que,

uma mudança de perspectiva socialé imperativa. Por um tempo demasiadamente longo os problemas das pessoas portadoras de deficiências têm sido compostos por uma sociedade que inabilita, que tem prestado mais atenção aos impedimentos do que aos potenciais de tais pessoas (Declaração de Salamanca, 1994, p. 4).

Esta é uma afirmação muito relevante, pois reconhecendo que o campo do social opera uma produção da deficiência, deixando em evidência apenas a limitação que ela impõe e contribuindo para a marginalização, defende a transformação desta realidade.

Desde o final da década de 1980, a legislação brasileira $^{7}$ já vinha afirmando o direito à educação das crianças com deficiência, instituindo a obrigação do Estado a se responsabilizar pela inserção da Educação Especial no sistema de ensino. Esta política estava ainda atrelada à perspectiva da integração na medida em que a educação das pessoas com deficiência devia ocorrer em instituições especiais de ensino e, apenas se o indivíduo fosse capaz de se integrar ao sistema regular de ensino, seria aceito nas instituições educacionais regulares.

Após a Declaração de Salamanca (1994) é promulgada uma nova Lei de Diretrizes e Bases da Educação no Brasil em 1996 (Lei n. 9394 de 1996) que afirma pela primeira vez que a educação de pessoas com deficiência deve acontecer preferencialmente na rede regular de ensino e que apenas deve-se recorreràs instituições especiais quando se esgotarem todas as possibilidades na escola regular.

No âmbito legal, opera-se um desvio na direção das políticas governamentais voltadas às pessoas com deficiência a partir da consideração, surgida na década de 1990, de que existem no campo social práticas inferiorizantes das pessoas com deficiência e do reconhecimento da necessidade de que a sociedade se organize para incluí-las. Parece-me que assim caminhamos na direção de entender que para além das limitações, há também possibilidades de realização na vida dessas pessoas.

Os avanços das estatísticas da inclusão (Brasil, 2008) são significativos, mas o que se torna importante perguntaré como tem acontecido a inclusão nessas escolas. Vale questionar quais práticas têm sido desenvolvidas ali e que processo de produção subjetiva tem se engendrado nesses espaços. Outra questão importante é se a entrada dessas pessoas na escola regular tem contribuído para construir outra forma de conceber e lidar com a deficiência.

Foucault identifica a partir do final do século XVIII o surgimento de uma nova tecnologia de poder, que vai exercer outra forma de controle, não mais sobre os indivíduos, mas sobre a totalidade da população, sobre toda a massa de pessoas que compõe a sociedade. Um poder que se exerce sobre a vida em toda sua extensão, um biopoder, que será sustentado por uma biopolítica (Foucault, 1988), sistema que busca saber e controlar os processos próprios da vida, como os nascimentos, óbitos, a velhice, entre outros. Essa nova tecnologia de poder vai fazer emergir novos campos e objetos de saber, principalmente a estatística, que vai estudar a proporção de óbitos e nascimentos, a fecundidade de uma população, a incidência de doenças, a existência de anomalias diversas.

Este autor diferencia o poder disciplinar do biopoder, mas afirma que no século XIX estão em cena mecanismos disciplinares e de regulamentação que se superpõem e se articulam, pois atuam em níveis diferentes, o dos corpos e o das populações. O que interessa no biopoder é incidir na população de forma intensiva pelo conhecimento sobre o homem-espécie e seus mecanismos biológicos. Há um elemento que vai circular entre esses dois modos de poder, que é a "norma". A norma que disciplina um corpo e que regulamenta uma população. No biopoder a

\footnotetext{
A Lei n. 7853 de 1989, dispõe sobre o apoio às pessoas com deficiência, sua integração social, sobre a Coordenadoria Nacional para a Integração da Pessoa Portadora de Deficiência (CORDE), institui a tutela jurisdicional de interesses coletivos ou difusos dessas pessoas, disciplina a atuação do Ministério Público, define crimes e dá outras providências.
} 
normalização acontece de forma muito mais sutil e por isso mesmo mais eficaz, pois por meio das estatísticas e dos saberes que vão dizer o que é saudável e o que não é ou como ter uma vida mais longa, o controle se transporta para dentro das famílias, numa descentralização do poder.

A partir da década de 1950 e das transformações tecnológicas que desde então vêm ocorrendo, nos meios de comunicação principalmente, esta descentralização se intensifica e o poder se capilariza. No contexto da biopolítica reproduzem-se modos de existência, modos hegemônicos de vida, de maneira sutil e eficaz. Esta reprodução se dá não apenas através das grandes instituições, mas por mecanismos presentes no cotidiano de nossas práticas, difundidos principalmente pelos meios de comunicação de massa. A lógica normalizante, e consequentemente excludente, se processa no dia-adia, no cotidiano da vida de todos nós. Este processo contribui, não exatamente para a exclusão, mas para a fixação dos indivíduos em determinados nichos na sociedade: os deficientes, os pobres, os punks, os nerds, os saudáveis, etc.

As políticas públicas de inclusão, apesar de representarem a possibilidade de intervir na lógica de exclusão da pessoa com deficiência, são redimensionadas na forma como a cegueira e outras deficiências assumem um "fechamento de sentido" (Martins, 2006) que impede o exercício da diferença.

Como fazer resistência a esta biopolítica que parece se infiltrar de maneira tão eficiente em nossas vidas? Gostaria aqui de pensar em práticas de resistência pelo que chamarei de políticas de vida, de uma política que se dá no meio micropolítico ${ }^{8}$, das práticas cotidianas, das relações, que não sejam levadas pelos automatismos que a lógica do biopoder impõe, e que possam fazer diferente e não atualizar esta hegemonia da normalidade.

Segundo Felix Guattari (2005), a subjetividade vai se constituindo a partir de um processo de subjetivação, de produção subjetiva. Nesse processo ocorre o engendramento de forças das mais diversas naturezas, que vão produzir formas de estar no mundo, formas de relação com o trabalho, tipos de família e de relação com a ordem social, ou com o que é diferente de nós, por exemplo. Isso não vai acontecendo apenas por meio das grandes estruturas de produção das relações sociais, mas também no tecido de nossas relações cotidianas.

Considerando a intensidade da produção de subjetividade no mundo contemporâneo, é importante sublinhar a produção singular, que se distancia de uma perspectiva normalizante e ortopédica que produz fixação, que possibilita que os modos singulares da existência na cegueira possam ganhar expressão e, assim, que as pessoas com deficiência possam circular, na cidade, mas principalmente na vida, nas relações.

Em relação às questões que envolvem a deficiência visual, na forma como a ausência do sentido da visão passou a ser considerada como déficit ou desvio, percebe-se que já se coloca aí um limite, muitas vezes intransponível. O fato de uma pessoa ser cega ou ter baixa visão por si só já impõe uma limitação. A exclusão, nesse caso, não vai se dar apenas por uma questão social, ela acontece no encontro com a deficiência visual, em que incidem sobre esta pessoa tais concepções hegemônicas de cegueira mencionadas anteriormente. Assim, a marginalização acontece de forma mais intensa e incapacitante. O déficit é enfatizado, ficando encobertas as estratégias singulares e as possibilidades que cada um constrói em sua existência sem a visão. A ênfase dada ao déficit se configura como uma força no processo de produção de subjetividade, fazendo existir modos de vida com a cegueira como uma "subjetividade deficiente", em que as forças incapacitantes e impeditivas se superpõem, produzindo um sujeito que se acredita incapaz.

\section{A cegueira na escola e o manejo dos "encontros mistos"}

A entrada de uma criança na escola significa sua inserção num determinado conjunto de valores e discursos que são produzidos e multiplicados ali. Por esta razão é importante pensarmos que produção subjetiva tem sido operada pelas políticas de inclusão praticadas na escola. $\mathrm{O}$ espaço educacional não se limita a um local onde se executam técnicas de aprendizagem ou de socialização (Guattari, 1987).

\footnotetext{
8 Para Guattari e Rolnik (2005, p. 155), micropolítica refere-se ao cruzamento entre os diferentes modos de apreensão de uma problemática. Segundo os autores, esses modos não são apenas dois: "sempre haverá uma multiplicidade, pois não existe uma subjetividade de um lado e, do outro, a realidade social material.” No campo micropolítico observam-se conexões entre as linhas de força (molar e molecular) que se dão no socius, nas relações, no cotidiano.
} 
As relações de forças que ali se presentificam, envolvendo alunos, professores, a semana de provas, a família, e outros elementos diversos daquele contexto, configuram-no como um importante dispositivo produtor de subjetividade.

Nesse sentido, a escola pode ser reprodutora da lógica dominante, capitalista e serializada ou possibilitar a emergência de "processos de singularização", produção de diferença, "construção de modos de relação com o outro, modos de produção, modos de criatividade, que produzam uma subjetividade singular." (Guattari e Rolnik, 2005, p. 22).

Ante essa produção de massa que se faz no cotidiano, não basta contar apenas com as políticas governamentais, que traçam ações amplas, que dificilmente conseguem dialogar com as práticas locais e singulares de onde tal ação se dá. É na micropolítica que a inclusão deve ser pensada. Nesse sentido, queremos afirmar a importância do que Martins vai denominar "encontros mistos" (Martins, 2006) entre cegos e videntes.

Os "encontros mistos" não são simplesmente encontros entre pessoas cegas e pessoas que veem, mas se referem ao encontro entre a cegueira e o mundo. Este autor vai dizer que esses encontros podem provocar a desestabilização das concepções hegemônicas de cegueira, pois colocam em cena diversas formas de lidar com ela, desde aquelas que marcam a cegueira como desgraça, que aparecem em falas como "coitadinho do ceguinho" até aquelas outras que lidam com a cegueira como um dom superior, a imagem típica do cego Tirésias, o cego que vê mais. $\mathrm{Na}$ confrontação com as experiências singulares de quem vive sem a visão percebe-se que a cegueira não é definida apenas por sua face triste, assustadora, limitante, mas comporta também a produção de outros modos de estar no mundo. Esses encontros não são a garantia desta desestabilização, já que podem também atualizar tais concepções hegemônicas, mas é apenas por meio deles que se podem produzir outras concepções de cegueira, longe daquelas que são hegemônicas.

A escuta das narrativas (Martins, 2006) próprias de quem vive a experiência da cegueira é uma prática que poderíamos considerar como inserida nas politicas de vida que fazem ante o biopoder. As narrativas singulares permitem ganhar expressão o vivido, o vívido desta experiência, diferentemente do discurso homogeneizante que não representa a vida de ninguém, mas uma generalização que reduz essas existências a um único modo. É apenas no encontro que é possível deslocar essas concepções hegemônicas e produzir outro modo de relação com a cegueira.

A inclusão é uma política de governo que se pretende universal, mas isso não garante sua efetividade, que vai estar atrelada às relações singulares que se dão no local onde se desenrola. Assim, falar de inclusão é levar em conta as condições práticas de sua realização, que envolvem certamente as condições materiais, mas também considerar que as pessoas que a vivenciam diretamente podem contribuir para sua construção, sejam eles professores, alunos, videntes ou não videntes. A inclusão se configura assim como uma construção coletiva composta pela escuta das narrativas, não só da experiência da cegueira, mas de todos que vivem este encontro. A articulação das políticas de governo com as narrativas das pessoas que a vivenciam é importante, pois possibilita que os sujeitos façam parte da política, engendrando aí também outros modos de produção de subjetividade, pela participação e pela efetiva inclusão.

\section{O trabalho na ERI}

O momento de passagem da escola especial para a escola regular inclusiva não é trivial, pois envolve não só uma mudança de colégio, aflitiva para muitos adolescentes, mas também a saída de um espaço totalmente voltado para a deficiência visual e a entrada em outro onde a questão da cegueira não é uma temática central. Isso torna a discussão do manejo dos "encontros mistos" fundamental naquela escola inclusiva.

A IE, por ser um espaço organizado para lidar com a cegueira e acolhê-la, para muitos usuários parece se configurar como um lugar protegido dos olhares de comiseração e do enfrentamento de situações em que se fazem

\footnotetext{
9 Tirésias é o personagem da tragédia de Sófocles, o Mito de Édipo, capaz de fazer as revelações do drama do incesto e do assassinato do próprio pai, vivenciado por Édipo, considerado “o cego que via mais” (Martins, 2006, p. 51).
} 
presentes tais concepções hegemônicas acerca da cegueira. Porém, esta instituição, inserida no campo das produções sociais da sociedade contemporânea, é atravessada pelas forças que atualizam visões incapacitantes acerca daqueles que não vêem.

Como manejo dos "encontros mistos" entende-se a forma como a escola se organiza para promover a inclusão, incluindo-se aí a existência ou não de espaços de discussão, a divisão das horas de trabalho dos professores entre a Educação Especial e a educação regular, a implantação de salas especializadas, a capacitação dos professores. Quando afirmamos a necessidade de trabalhar o manejo dos encontros queremos dizer que é fundamental que o coletivo da escola discuta e analise as concepções de cegueira que são corroboradas nestas práticas .

$\mathrm{Na}$ ERI que investigamos a inclusão dos alunos cegos e com baixa visão se dá principalmente através da Sala de Educação Especial, uma sala que concentra todas as ações relacionadas a estes alunos. Lá são impressos os textos em Braille ou com letra ampliada, é o local onde os jovens com deficiência visual têm aulas de apoio, onde ficam os livros em Braille, onde estão os arquivos com as informações dos alunos com deficiência visual e é também um ponto de encontro, onde a maioria destes jovens passa o recreio. NaERI há 13 alunos com deficiência visual distribuídos em 10 turmas inclusivas. As ações em relação aos alunos são realizadas por professores que se prontificam a fazê-lo, apenas dois deles têm horas de sua carga horária reservadas para o trabalho relativo à Educação Especial.

A partir dos depoimentos de alunos e professores que entrevistamos percebemos que a inclusão se faz naquela ERI contando principalmente com a iniciativa pessoal dos professores e dos alunos videntes, que vão criando estratégias e colaborando para garantir o aprendizado e a permanência dos alunos com deficiência visual no colégio. Durante esse período que estivemos naquele espaço estabelecemos contato com iniciativas muito interessantes.

Porém, percebemos que o fato de a inclusão se realizar "pela tangente", como afirmou uma das professoras entrevistadas, referindo-se ao fato de apenas alguns professores se engajarem na promoção da inclusão dos alunos, faz com que continuem existindo na escola práticas, mesmo que sutis, que reafirmam visões incapacitantes em relação às pessoas cegas e com baixa visão.

A maneira como a inclusão é realizada na ERI representa o que foi possível nestes quatro anos de criação do Setor de Educação Especial. Os avanços e limitações respondem não só às questões sociais, mas também das determinações do Ministério da Educação. A prática da inclusão é atravessada por inúmeros vetores, não apenas de políticas públicas, também de políticas de vida. As políticas públicas não garantem por si só a efetividade da inclusão, que deve estar atrelada ao trabalho acerca do manejo dos "encontros mistos", que possa potencializá-los no sentido de serem produtores de novas relações com a deficiência.

Este manejo envolve a todos, cegos e videntes, alunos e professores, porque as concepções hegemônicas de cegueira se atualizam tanto a partir dos cegos, quanto pelos videntes. De um modo ou de outro somos todos afetados por tais concepções de cegueira.

Nossa escolha metodológica nos leva a uma aproximação das narrativas próprias das pessoas que vivenciam o contexto da escola inclusiva no sentido de pensar o que o encontro entre cegos e videntes pode produzir e que estratégias de inclusão vão sendo construídas ali. A contribuição que este trabalho pretende se coloca na perspectiva de, apontando para estratégias coletivas, vislumbrar outra relação com a cegueira, que resgatando o processo de construção histórica e de institucionalização da deficiência possa promover uma inclusão que questione os processos de exclusão nela contidos.

\section{REFERÊNCIAS}

Brasil. (1989). Direitos das Pessoas Portadoras de Deficiência. Lei $\mathrm{n}^{0} 7.853$ de 24 de outubro de 1989. Recuperado 02 de jul. 2008, em http:// www.portal.mec.gov.br

Brasil. (1996). Lei de Diretrizes e Bases da Educação. Lei no 9.394 de 1996. Recuperado 05 jul. 2008, em http://www.portal.mec.gov.br

Brasil. (2001). Plano Nacional de Educação. Lei n 10.172 de 2001. Recuperado em 10 jul. 2008, em http://www.portal.mec.gov.br 
Brasil. (2008). Súmula: Política nacional de educação especial na perspectiva da educação inclusiva. Cadernos CEDES (28), 75, 269-273. Campinas. Recuperado 05 set. 2008, em http:/ / www.cedes.unicamp.br

Espanha. (1994). Declaração de Salamanca. Recuperado 09 jun. 2008, em http:/ /www.portal.mec.gov.br

Foucault, M. (1988). Direito de morte e poder sobre a vida. In: Foucault, M. História da Sexualidade 1: A vontade de saber. Rio de Janeiro: Edições Graal.

Foucault, M. (1996). Conferência V. In: Foucault, M. As verdades e as formas jurídicas. Rio de Janeiro: NAU Editora.

Foucault, M. (2001). Aula de 15 de janeiro de 1975. In: Foucault, M. Os anormais. São Paulo: Martins Fontes.

Foucault, M. (2007). Vigiar e punir. Petrópolis: Vozes.

Guattari, F. (1987). As creches e a iniciação. In: Guattari, F. Revolução molecular: Pulsação política do desejo. São Paulo: Brasiliense.

Guattari, F., Rolink, S. (2005). Micropolítica: Cartografias do desejo. Petrópolis: Vozes.

Lima, L. (2008). A cegueira na escola regular: A inclusão pelo encontro. Trabalho de Conclusão de curso de Graduação em Psicologia. Universidade Federal Fluminense, Rio de Janeiro.

Martins, B. S. (2005). Políticas sociais na deficiência: Exclusões perpetuadas. Recuperado 01 mai 2008, em http:/ / www.ces.uc.pt/publicacoes/228/228.php

Martins, B. S. (2006). E se eu fosse cego: Narrativas silenciadas da deficiência. Lisboa: Edições Afrontamentos.

Sassaki, R. K. (2003). Panorama Geral da Inclusão Social. Anais do I Seminário de Políticas Públicas do município de Limeira sobre pessoas com deficiência. Recuperado 05 set. 2008, em http://www.ceset.unicamp.br/

Recebido: 15/05/2009

Received: 05/15/2009

Aprovado: 06/07/2009

Approved: 07/06/2009

Revisado: 11/12/2009

Reviewed: 12/11/2009 